\title{
Disturbance Observer Based Heave Compensation Control for Benthic Coring Drill
}

\author{
Y. Guo ${ }^{*}, 1,2$, Y.P. Jing ${ }^{1}$, M. Jiang ${ }^{1}$ and B.W. Luo ${ }^{1}$ \\ ${ }^{I}$ Engineering Research Centre of Advanced Mining Equipment, Ministry of Education, Hunan University of Science and \\ Technology, HuNan Xiangtan 411201, China \\ ${ }^{2}$ Key Laboratory of Lightweight and Reliability Technology for Engineering Vehicle, Education Department of Hunan \\ Province, Changsha University of Science \& Technology, HuNan Changsha 410004, China
}

\begin{abstract}
Severe environment in deep ocean affects operating reliability and security of coring drill. Adopting heave motion signal measured by accelerometer to confirm heave compensation of coring drill, the compensation control method is proposed using disturbance observer to restrain the disturbance. Then, the disturbance observer is designed. The heave motion simulation for coring drill is done with this control method, and the results show that the heave motion compensation control of coring drill using disturbance observer avoids the disturbance with high tracking quality, and provides high reliability and security to coring drill operating.
\end{abstract}

Keywords: Coring drill, disturbance observe, heave motion, hydraulic system, path tracking, winch.

\section{INTRODUCTION}

With the development of resource exploration in deep sea, the working depth for resource exploration equipment is deeper, and the working environment is more abominable [1, 2]. The power and control signal for benthic coring drill is acquired by umbilical cable. Under the effects of surge, wave and flow in deep sea, horizon and vertical movements are produced. The heave motion in vertical makes the loads in umbilical cable increase, which would destroy the umbilical cable making coring drill dropped, and reduce the working reliability and security of benthic coring drill. In order to avoid the effects on abominable environment, active heave compensation control is studied widely. According to ship movement and cylinder displacement, $\mathrm{Hu}$ [3] proposes the compensation control method to heave motion with crown block compensation device; Yang [4] adopts a novel approximate feedback linearization approach to realize the heave motion compensation of a spatial 6-DOF hydraulic parallel manipulator; Kord [5] uses linear control technology to compensate the ship heave motion; Johansen [6] establishes the heave compensation system for crane on ship using synchronous control to wave; considering the loads generated by abominable environment, Skaare and Egeland [7] design the complex controller of force and displacement. Benthic coring drill is draw by winch under the inhibition of weight and space. However, the study on active compensation control using winch is very little [8].

*Address correspondence to this author at the Engineering Research Centre of Advanced Mining Equipment, Ministry of Education, Hunan University of Science and Technology, HuNan Xiangtan 411201, China;

+86-15974184466; Fax: +86-0731-58290624; E-mail: gy012702@163.com
In the paper, the active heave motion compensation control using winch is carried on. Using ship heave motion displacement measured by accelerometer to calculate the heave compensation value of benthic coring drill, combining disturbance observe to restrain the disturbance of sever environment, the active heave compensation control system is put forward, which improves heave motion tracking precision of the drill, and ensures the working reliability and security.

\section{COMPOSITION OF HEAVE MOTION SYSTEM FOR BENTHIC CORING DRILL}

The heave motion compensation system using winch is shown in Fig. (1). The effects of environment on coring drill are acquired through ship heave motion measured by accelerometer. The controller calculates the heave motion compensatory value according to the moving signal of a ship. Combing disturbance observer to control proportional directional valve, the heave motion track of winch is realized. When the accelerometer detects the ship sinkage under ocean disturbance load, the controller calculates the compensation value and makes proportion direction valve work on the underside. A part of high pressure oil flows into the brake cylinder, which makes the brake open. Other high pressure oil flows into the hydraulic motor. The hydraulic motor makes the winch running in counter-clockwise, and the umbilical cable is taken back. When the accelerometer detects the ship raise under ocean disturbance load, the controller calculates the compensation value and makes proportion direction valve work on the upside. A part of high pressure oil flows into the brake cylinder, which makes the brake open. Other high pressure oil flows into the hydraulic motor. The hydraulic motor makes the winch run in clockwise, and the umbilical cable is released. 


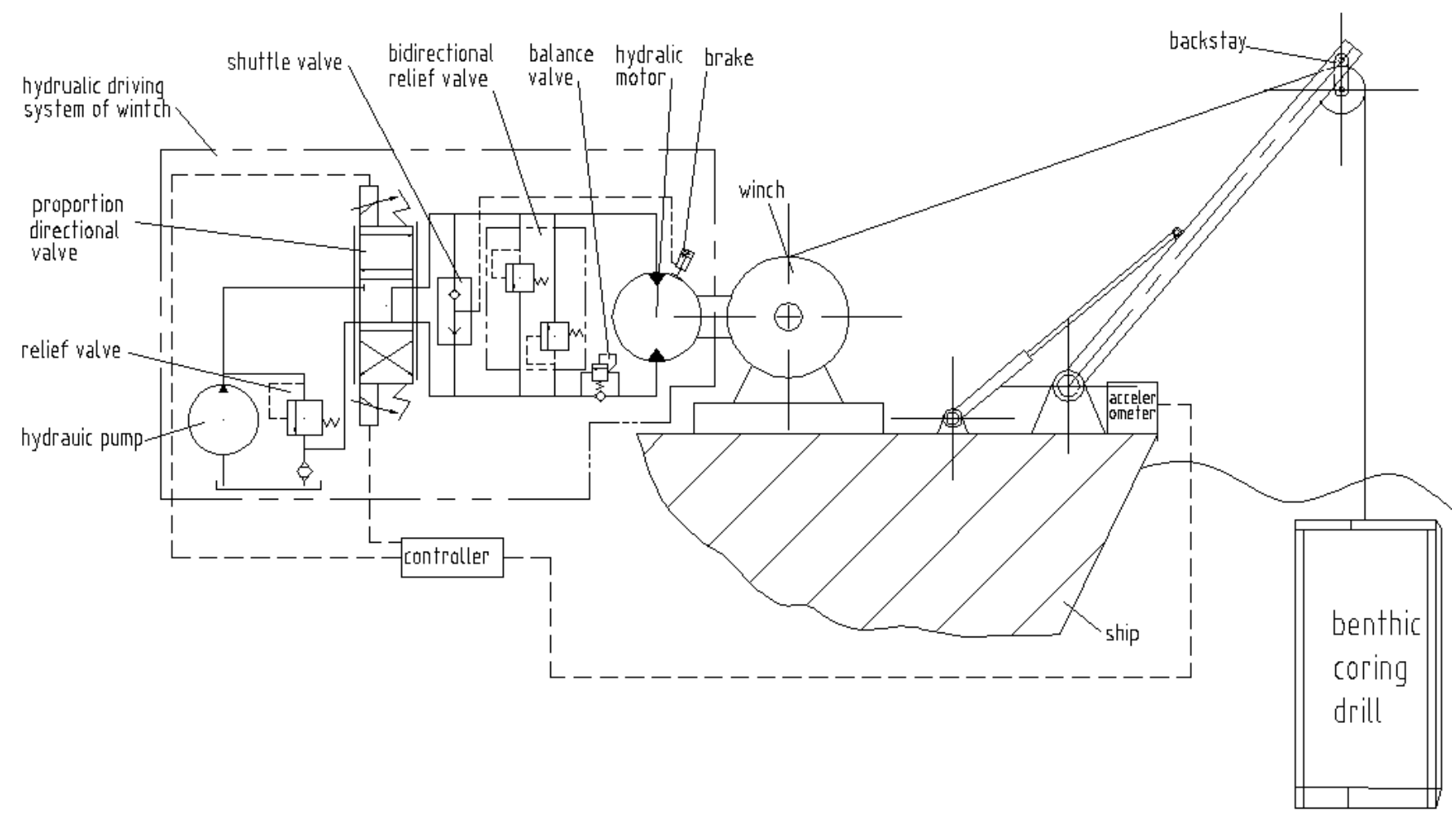

Fig. (1). Heave motion compensation system scheme of coring drill.

Neglecting the elastic deforming of umbilical cable, the relation of winch movement, coring drill movement and ship movement is written as follows:

$W(t)=S(t)+D(t) \ldots$

where, $W(t)$ is moving displacement of winch; $S(t)$ is moving displacement of ship; $D(t)$ is moving displacement of benthic coring drill.

To ensure working reliability and security of benthic coring drill, the moving displacement of coring drill must be very small, $D(t) \approx 0$. Then, the compensation control of coring drill movement is transformed to reverse movement tracking of winch moving displacement $W(t)$ and ship moving displacement $S(t)$. Therefore, the reverse moving track can be realized through proportion directional valve control winch moving, which ensures the compensation control of coring drill movement.

\section{MATHEMATICAL MODEL OF HEAVE COMPENSATION SYSTEM FOR BENTHIC CORING DRILL}

\section{Moving Equation of Winch}

The dynamic character of coring drill drawing through hydraulic winch is affected by loads. The load is composed by inertia force, viscosity force and disturbance force by wave. The torque equation of hydraulic winch is as follows:

$$
J_{d r} \ddot{\theta}+B_{d r} \theta+F_{t}(\theta, \dot{\theta}, t) R_{d r}=\left(p_{i}-p_{o}\right) D_{m} \cdots
$$

where, $\theta$ is the revolving angle for roller of hydraulic winch, $\mathrm{rad} ; J_{d r}$ is equivalent revolve inertia, $\mathrm{kg} \cdot \mathrm{m}^{2} ; B_{d r}$ is the viscosity coefficient, $N \cdot s \cdot \mathrm{rad}^{-1} ; R_{d r}$ is the diameter of roller, $m ; p_{i}$ is the inlet pressure of hydraulic motor for winch, $P a ; p_{o}$ is the outlet pressure of hydraulic motor for winch, $p a ; D_{m}$ is equivalent displacement considering gear ratio, $D_{m}=V_{m} i, V_{m}$ is the displacement of driving motor for hydraulic winch, $\mathrm{m}^{3} \cdot \mathrm{rad}^{-1}, i$ is the gear ratio of planet retard for hydraulic winch; $R_{d y}$ is the diameter of roller for hydraulic winch, $m ; F_{t}(\theta, \theta, t)$ is the equivalent load on umbilical cable, $N$;

$F_{t}(\theta, \theta, t)=m_{r d} g-\rho_{w} g V_{r d}+f(\theta, \theta, t) \ldots$

where, $m_{r d}$ is the mass of coring drill, $\mathrm{kg} ; \rho_{w}$ is the density of seawater, $\mathrm{kg} \cdot \mathrm{m}^{-3} ; g$ is the acceleration of gravity, $\mathrm{kg} \cdot \mathrm{m} \cdot \mathrm{s}^{-2} ; V_{r d}$ is the volume of coring drill, $\mathrm{m}^{3} ; f(\theta, \dot{\theta}, t)$ is the disturbance load of sever environment in deep sea, $N$.

\section{Mathematical Model of Hydraulic System for Coring Drill Heave Motion Control}

Suppose the connection pipe of proportion directional valve and driving motor is disposed symmetry, the pressure in the working chambers is the same, the inside and outside leakage of hydraulic motor is laminar flow, treating bulk 
modulus of hydraulic oil as constant and ignoring the pressure loss in connecting pipe, the flow into and out of the hydraulic motor are written as follows:

$\left\{\begin{array}{l}q_{i}=D_{m} \dot{\theta}+C_{i m}\left(p_{i}-p_{o}\right)+C_{e m} p_{i}+\frac{V_{1}}{\beta_{e}} \dot{p}_{1} \\ q_{o}=D_{m} \dot{\theta}+C_{i m}\left(p_{i}-p_{o}\right)-C_{e m} p_{o}-\frac{V_{2}}{\beta_{e}} \dot{p}_{o}\end{array} \cdots\right.$

where, $q_{i}$ is the flow into hydraulic motor, $\mathrm{m}^{3} \cdot \mathrm{s}^{-1} ; q_{o}$ is the flow out of hydraulic motor, $\mathrm{m}^{3} \cdot \mathrm{s}^{-1} ; \theta$ is revolving angle for roller of hydraulic winch, $\mathrm{rad} ; C_{i m}$ is inside leakage coefficient of hydraulic motor, $\mathrm{m}^{3} \cdot \mathrm{s}^{-1} \cdot \mathrm{Pa}^{-1} ; C_{e m}$ is outside leakage coefficient of hydraulic motor, $\mathrm{m}^{3} \cdot \mathrm{s}^{-1} \cdot P \mathrm{a}^{-1} ; V_{1}$ is the inlet chamber of hydraulic motor, $\mathrm{m}^{3} ; V_{2}$ is the outlet chamber of hydraulic chamber, $\mathrm{m}^{3} ; \beta_{e}$ is the bulk modulus of hydraulic oil, $P a$.

Neglecting the dynamic effects of the pipe between proportion valve and hydraulic motor, the flow through the proportion valve is equivalent to the flow out of the motor. The flow through proportion valve can be written as follows by orifice flow formula.

$$
\begin{aligned}
& q_{i}=c_{d} \psi x_{p v} \sqrt{\frac{2}{\rho} \Delta p_{1}}, \Delta p_{1}=\left\{\begin{array}{c}
p_{s}-p_{i} ; x_{p v}>0 \\
p_{i}-p_{T} ; x_{p v}<0
\end{array} \ldots\right. \\
& q_{o}=c_{d} \psi x_{p v} \sqrt{\frac{2}{\rho} \Delta p_{2}}, \Delta p_{2}=\left\{\begin{array}{c}
p_{s}-p_{i} ; x_{p v}<0 \\
p_{i}-p_{T} ; x_{p v}>0
\end{array} \quad \cdots\right.
\end{aligned}
$$

where, $c_{d}$ is flow coefficient ; $\psi$ is Proportional valve port area gradient, $m ; x_{p v}$ is the spool displacement of proportional valve, $m ; \rho$ is the density of oil, $K g \cdot \mathrm{m}^{-3} ; p_{i}$ is the pressure in inlet chamber of hydraulic motor, $\mathrm{Pa} ; \mathrm{p}_{o}$ is the pressure in outlet chamber of hydraulic motor, $P a ; p_{s}$ is the system pressure, $P a ; p_{T}$ is the pressure of return oil, $P a$.

Through control compensation, the relation between input of proportional directional valve and spool displacement can be written as follows using one order inertial.

$\dot{x}_{p v}=-\frac{1}{T_{p v}} x_{p v}+\frac{k_{p v}}{T_{p v}} u \ldots$

where, $x_{p v}$ is the spool displacement of proportion directional valve, $m ; T_{p v}$ is constant coefficient of time for proportion valve, $s ; k_{p v}$ is the gain of proportional valve, $m$.

\section{Linearization Model of Heave Compensation System for Benthic Coring Drill}

Proportional directional valve is zero four sides spool valve, four throttles are disposed symmetry. Having a linearization of throttle flow on spool displacement $x_{p v}=0$, we can get

$\left\{\begin{array}{l}q_{i}=K_{q} x_{p v}-K_{p} p_{i} \\ q_{o}=K_{q} x_{p v}+K_{p} p_{o}\end{array} \cdots\right.$

where, $K_{q}$ is the flow gain of throttle for proportion valve, $m^{2} \cdot s^{-1} ; K_{p}$ is the gain between flow and pressure, $m^{3} \cdot s^{-1} \cdot P a^{-1}$.

The transform function of heave motion for benthic coring drill is written as follows through the Laplace transformation to Eq.(2), Eq.(4), Eq.(7) and Eq.(8).

$$
\theta(s)=\frac{\frac{k_{p v} k_{q} D_{m}}{1+T_{p v} s} U(s)-\left(k_{c e}+\frac{V_{e}}{2 \beta_{e}} s\right) R_{d r} F_{t}(s)}{\frac{J_{d r} V_{e}}{2 \beta_{e}} s^{3}+\left(\frac{B_{d r} V_{e}}{2 \beta_{e}}+k_{c e} J_{d r}\right) s^{2}+\left(k_{c e} B_{d r}+D_{m}^{2}\right) s} \ldots
$$

where, $U(s)$ is the system control input of heave motion compensation, $F_{t}(s)$ is the disturbance load.

The viscosity coefficient $B_{d r}$ is very small. Neglecting the volume difference of inlet and outlet chamber in hydraulic motor, the dynamic equation of heave motion for benthic drill can be simplified as follows:

$$
\left\{\begin{array}{l}
\theta(s)=G_{u}(s) U(s)+G_{d}(s) F_{t}(s) \\
G_{u}(s)=\frac{k_{p v} k_{q}}{D_{m}\left(1+T_{p v} s\right)} \cdot \frac{\omega_{n}^{2}}{s\left(s^{2}+2 \xi \omega_{n} s+\omega^{2}\right)} \\
G_{d}(s)=-\left(\frac{k_{c e}}{D_{m}^{2}}+\frac{V_{e}}{2 \beta_{e} D_{m}^{2}} s\right) \cdot \frac{\omega_{n}^{2}}{s\left(s^{2}+2 \xi \omega_{n} s+\omega^{2}\right)}
\end{array}\right.
$$

where, $k_{p v}$ is the gain of proportion valve; $K_{q}$ is the flow gain of throttle for proportion valve; $D_{m}$ is equivalent displacement considering gear ratio; $T_{p v}$ is constant coefficient of time for proportion valve,

$$
s ; \omega_{n}=\sqrt{\frac{2 \beta_{e} D_{m}^{2}}{J_{d r} V_{e}}}
$$

is the hydraulic natural frequency, $V_{e}$ is the equivalent volume of inlet chamber for motor;

$\xi=\frac{k_{c e}}{D_{m}} \sqrt{\frac{\beta_{e} J_{d r}}{2 V_{e}}}$

is the hydraulic damping ratio, and $k_{c e}=k_{p}+C_{i m}+\frac{C_{e m}}{2}$ is the total gain of flow.

\section{DESIGN OF DISTURBANCE OBSERVER FOR BENTHIC CORING DRILL HEAVE MOTION SYSTEM}

According to the disturbance observer design method used by Velardocchia [9] and Traverso [10], the control 
block diagram of benthic coring drill with disturbance observer is designed as shown in Fig. (2). In the figure, $r$ is the reference input, $\theta$ is the revolve angel of roller, $d$ is the equivalent disturbance load on umbilical cable, $n$ is the measured noise. The disturbance observe is in range of double point line, $G_{n}(s)$ is the nominal model, $G_{u}(s)$ is control object, $\hat{d}$ is the estimate value of equivalent disturbance load, $Q(S)$ is the low pass filter. Disturbances observer uses the inverse of nominal model $G_{n}^{-1}(s)$ to estimate $u$. The estimate value $\hat{d}$ of equivalent disturbance load is acquired by the difference in the value of $\hat{u}$ and $u_{1}$. The controller inhibits the disturbance according to the feedback estimate value $\hat{d}$ of equivalent disturbance load. However, the accurate control object model $G_{u}(s)$ cannot be acquired, making the estimate value $\hat{d}$ hardly acquired. The design method of disturbance observe proposed by Kempf $[11,12]$ makes the design simplified to choose the nominal model $G_{n}(s)$ and the design of a low pass filter $Q(s)$.

\section{Nominal Model of Control Object}

According to Eq.(9), $G_{u}(s)$ can be transformed as follows

$$
G_{u}(s)=\frac{k_{e}}{s\left(1+T_{p v} s\right)} \cdot \frac{\omega_{n}^{2}}{s^{2}+2 \xi \omega_{n} s+\omega^{2}} \ldots
$$

where, $k_{e}=\frac{k_{q} k_{p v}}{D_{m}}$, equivalent coefficient; $k_{p v}$ is the gain of proportion valve; $K_{q}$ is the flow gain of throttle for proportion valve; $D_{m}$ is the equivalent displacement considering gear ratio; $T_{p v}$ is constant coefficient of time for proportion valve, $s ; \omega_{n}$ is the hydraulic natural frequency; $V_{e}$ is the equivalent volume of inlet chamber for motor; $\xi$ is the hydraulic damping ratio.
By Eq. (11), control object $G_{u}(s)$ can be obtained by integration, control object, inertia and two order vibration link in series. In practice, $\frac{V_{e}}{\beta_{e}}<<D_{m}^{2}$ and the hydraulic damper is relatively small making hydraulic natural frequency $\omega_{n}$ of two second concussion link very large, the gain characteristics in the low frequency range is very straight and the phase lag is small. Ignoring dynamic characteristics in high frequency of this link, the simplified nominal model is written as Eq. (12) shown.

$G_{u}(s)=\frac{k_{e}}{s\left(1+T_{p v} s\right)} \ldots$

where, $k_{e}$ is the equivalent coefficient; $T_{p v}$ is constant coefficient of time for proportion valve.

\section{Design of Low Pass Filter}

In Fig. (2), the function between system output $\theta$ and input parameters $u, d$ and $n$ can be written as Eq.(13).

$$
\left\{\begin{aligned}
G_{U \theta} & =\frac{G_{u}(s) G_{n}(s)}{G_{n}(s)+Q(s)\left[G_{u}(s)-G_{n}(s)\right]} \\
G_{D \theta} & =\frac{G_{u}(s) G_{n}(s)[1-Q(s)]}{G_{n}(s)+Q(s)\left[G_{u}(s)-G_{n}(s)\right]} \ldots \\
G_{N \theta} & =\frac{G_{u}(s) Q(s)}{G_{n}(s)+Q(s)\left[G_{u}(s)-G_{n}(s)\right]}
\end{aligned}\right.
$$

Suppose the bandwidth of low pass filter is $f_{q}$, when $f \leq f_{q}, Q(s) \approx 1, G_{D \theta}(s) \approx 0, \quad G_{U \theta}(s) \approx G_{n}(s)$, $G_{N \theta}(s) \approx 0$. This shows that in the bandwidth of low pass filter $Q(s)$, the disturbance observer makes system output equal to output through the nominal model having a strong inhibitory effect on the interference. In the design disturbance observer, $Q(s) G_{n}^{-1}(s)$ must be regular. According to the design method of Lee [13], $Q(s)$ is designed as follow:

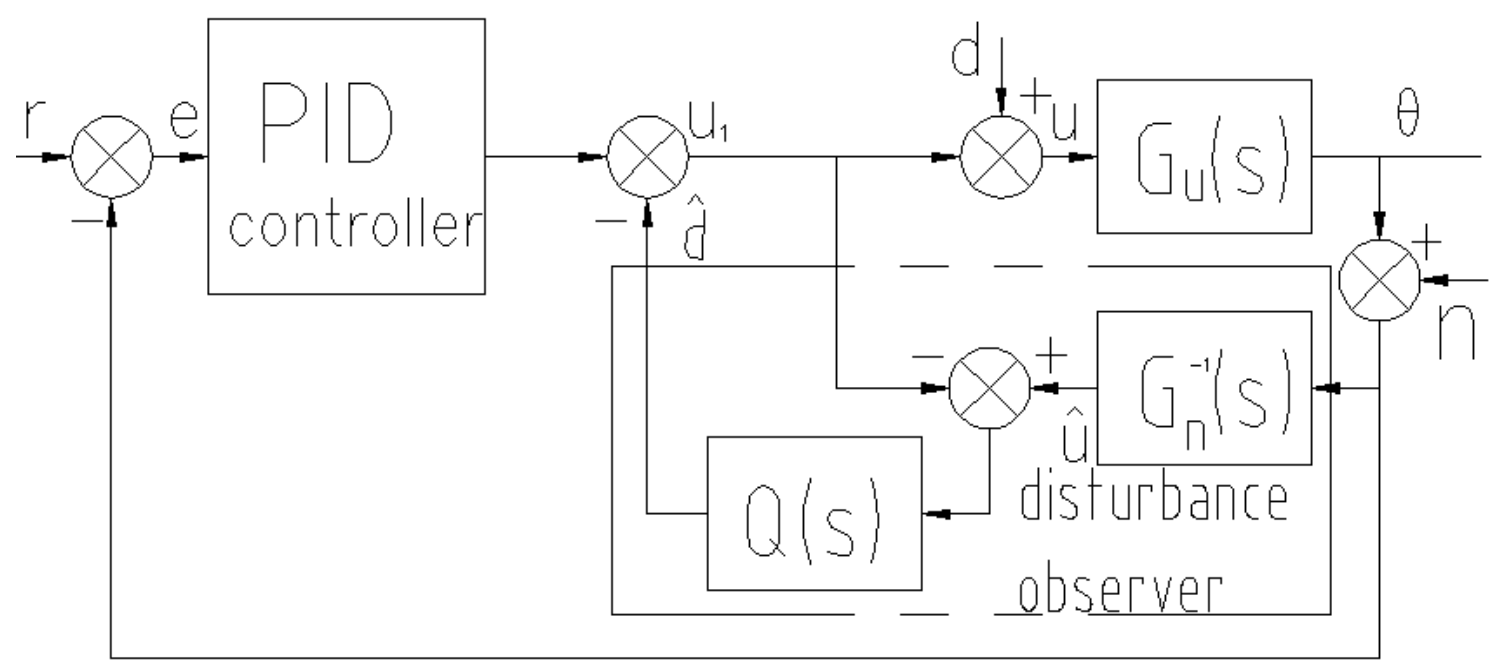

Fig. (2). Control block diagram of coring drill heave motion with disturbance observer. 
$Q(s)=\frac{\sum_{k=0}^{M} \alpha_{k}(\tau s)^{k}}{(\tau s+1)^{N}} \ldots$

where, $\alpha_{k}=\frac{N !}{(N-k) ! k !}$ is the coefficient; $N$ is the order of denominator ; $M$ is the order of numerator.

The control object $G_{u}(s)$ can be described by perturbation of nominal $\operatorname{model}_{n}(s)$ as Eq. (15) shows.

$G_{u}(s)=G_{n}(s)(1+\Delta(s)) \ldots$

where, $\Delta(s)$ is the perturbation of nominal model to actual control object. Therefore, the necessary and sufficient robust stable condition for $Q(s)$ is $\|Q(s) \Delta(s)\|_{\infty} \leq 1$.

By Eq. (11) (14), the low pass filter $Q(s)$ is written as follows:

$Q(s)=\frac{3 \tau s+1}{s^{3}+3 \tau s^{2}+3 \tau s+1} \ldots$

In Eq. (16), the value of $\tau$ decides the bandwidth of $Q(s)$, which should consider the ability of disturbance inhibition and the sensitivity of measured noise to choose.

\section{SIMULATION ANALYSIS OF HEAVE MOTION CONTROL FOR BENTHIC CORING DRILL}

The dead zone of proportional controller in the test can be eliminated by voltage compensation through soft control. Therefore, the effect of dead zone to system response can be ignored. According to Eq. (2) Eq. (16), the simulation model of heave motion control is built as Fig. (3). The value of main parameters is given in Table $\mathbf{1}$.

The heave motion control curve in the model is decided by ship heave motion. In the forth sea trial condition, the heave motion control curve $W(t)$ and the disturbance load $f(\theta, \theta, t)$ can be written as follows:

$\left\{\begin{array}{l}W(t)=1.3 \sin (0.84 t) \\ f(\theta, \dot{\theta}, t)=2000 \sin (0.84 t)\end{array} \ldots\right.$

Using this model, the simulations with and without disturbance observer are carried on. The heave motion curve of benthic drill without disturbance observer is shown in Fig. (4), and the curve with disturbance observer is shown in Fig. (5). The observer of disturbance load using disturbance observer is shown as Fig. (6).

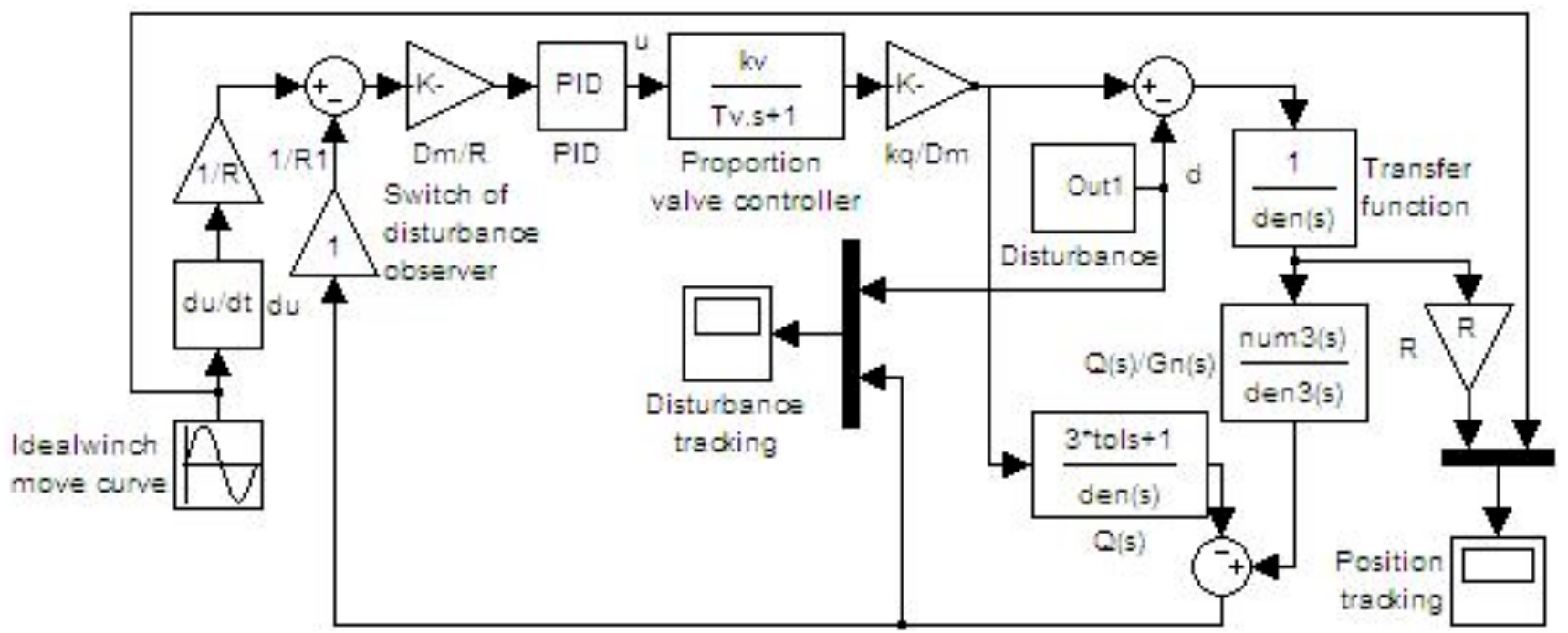

Fig. (3). Simulation model of heave motion control for coring drill.

Table 1. Parameters of Heave Motion Control Model for Coring Drill

\begin{tabular}{|c|c|c|c|}
\hline Parameters & Value & Parameters & Value \\
\hline \hline$K_{q} / m^{2} \cdot s^{-1}$ & 0.467 & $D_{m} / m^{3} \cdot \mathrm{rad}^{-1}$ & $1.43 \times 10^{-3}$ \\
\hline$T_{p v} / s$ & 0.06 & $\beta_{e} / P a$ & $1.7 \times 10^{9}$ \\
\hline$m_{r d} / \mathrm{kg}$ & 8000 & $k_{p v} / m$ & $6.25 \times 10^{-5}$ \\
\hline$R_{d r} / \mathrm{m}$ & 1 & $k_{c e} / \mathrm{m}^{3} \cdot \mathrm{s}^{-1} \cdot \mathrm{Pa}^{-1}$ & $6.48 \times 10^{-12}$ \\
\hline$J_{d r} / \mathrm{kg} \cdot \mathrm{m}^{2}$ & 1028 & $V_{e} / \mathrm{m}^{3}$ & $4 \times 10^{-3}$ \\
\hline
\end{tabular}




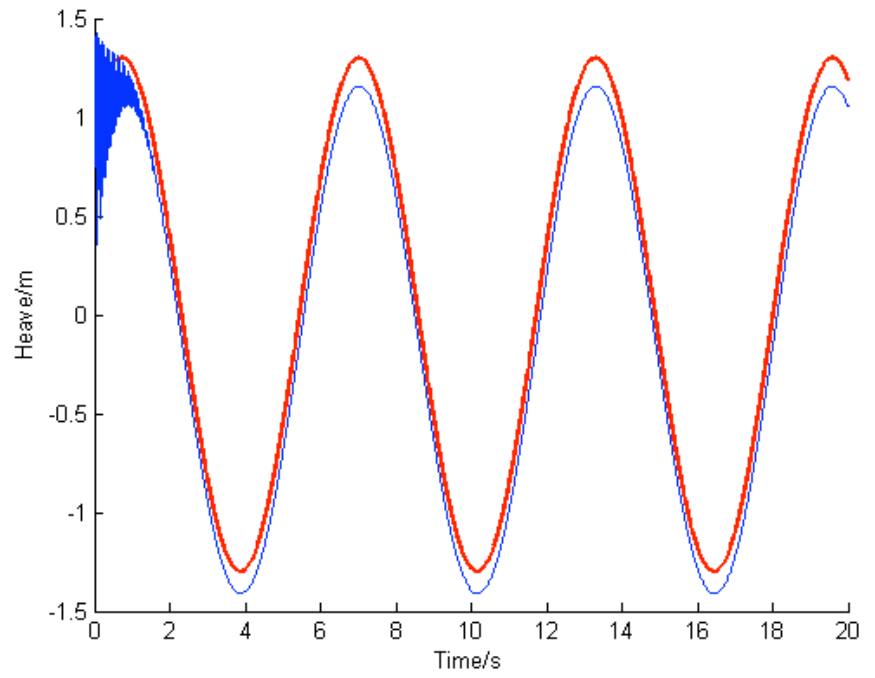

Fig. (4). Drill moving curve without disturbance observer.

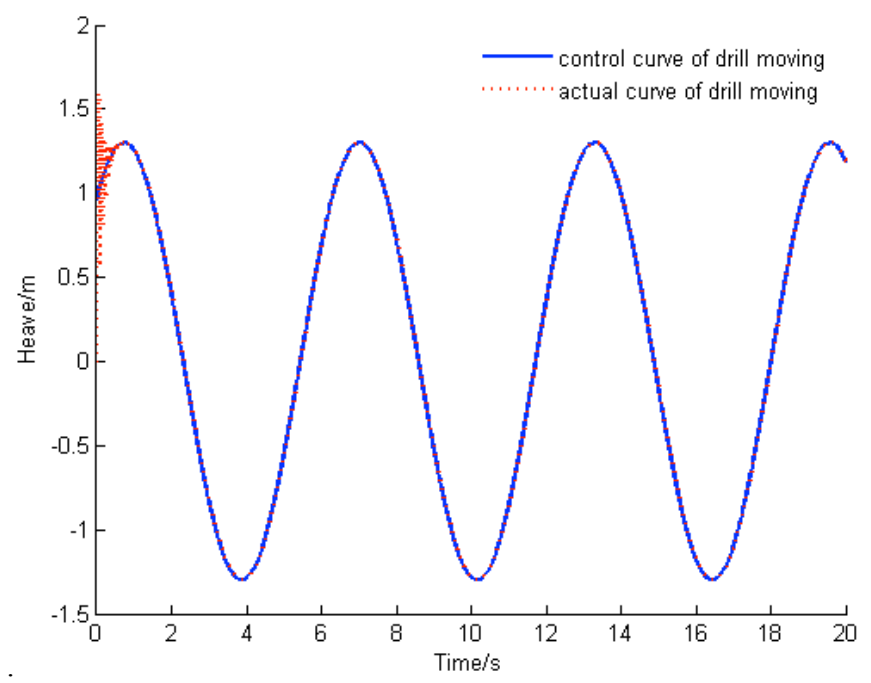

Fig. (5). Drill moving curve with disturbance observer.

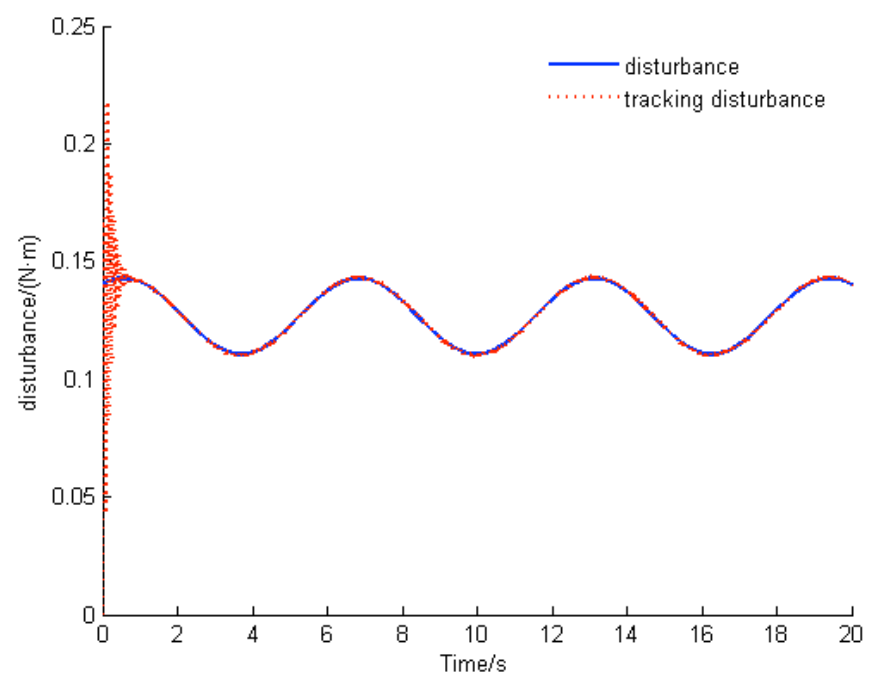

Fig. (6). Observed disturbance curve.

The figures show that the compensation system without disturbance observes works in steady status after $1.513 \mathrm{~s}$. However, the compensation systems with disturbance observe works in steady status after $1.29 \mathrm{~s}$, and the tracing disturbance load achieves steady status in $0.822 \mathrm{~s}$. The responses of the compensation system with disturbance observe is quicker than the compensation system without disturbance observes.

The figures also show that the maximum relative error of disturbance load between the acquirement of disturbance observe and the actual value is $11.9 \%$ after reaching the steady-state, which realize the good tracking precision of disturbance load. The minimum relative error of heave motion displacement acquired without disturbance observe to ideal moving displacement is $15.1 \%$, and the maximum relative error of heave motion displacement acquired with disturbance observe to ideal moving displacement is only $6.5 \%$. Therefore, the control with disturbance observe improves the heave motion tracking accuracy of benthic coring drill, and also avoid disturbance of environment load to benthic drill control.

\section{CONCLUSION}

Using accelerometer measure ship heave motion to decide heave motion compensation value of benthic coring drill, the heave motion compensation control model using disturbance observe is designed. Using this model, the maximum relative disturbance load error is $11.9 \%$ and the maximum relative displacement tacking error is $6.5 \%$. The control with disturbance observe makes heave motion control of benthic drill have a high tracking precision and disturbance inhibition, which can avoid the disturbance of environment load to benthic drill control and ensure the working reliability and security of the drill.

\section{CONFLICT OF INTEREST}

The authors confirm that this article content has no conflict of interest.

\section{ACKNOWLEDGEMENTS}

The authors thank the reviewers for their valuable comments and the support by grants from National High Technology Research and Development Program of China (No. 2012AA091301), Key Laboratory of Lightweight and Reliability Technology for Engineering Vehicle, College of Hunan Province (No. 2012KFJJ04), Scientific Research Fund of Hunan Provincial Education Department(No. 13C316), Hunan Provincial Natural Science Foundation of China (No. 14JJ6029) and Hunan Provincial Key Laboratory of Health Maintenance for Mechanical Equipment (No. 201305).

\section{REFERENCES}

[1] K. D. Do, and J. Pan, "Nonlinear control of an active heave compensation system", Ocean Engineering, vol. 35, pp. 558-571, April, 2008.

[2] W. L. Yang, Z. Y. Zhang, and A. Q. Zhang, "Study on active heave compensation system for underwater vehicle", The Ocean Engineering, Vol. 25, pp. 68-73, March, 2007.

[3] Q. Hu, S. J. Liu, and H. Zheng, "Design and implementation of model test installation of heave compensation system of deep-sea mining", Journal of Central South University of Technology, Vol. 18, pp. 642-649, November, 2011.

[4] C. Yang, S. Zheng, O. O. Peter, Q. Huang, and J. Han, "Approximate Feedback Linearization Control for Spatial 6-DOF 
Hydraulic Parallel Manipulator", The Open Mechanical Engineering Journal, vol. 5, pp. 117-123, February, 2011.

[5] U. A. Korde, "Active heave compensation on drill-ships in irregular waves", Ocean Engineering, Vol. 25, pp. 541-561, July, 1998.

[6] T. A. Johansen, T. I. Fossen, S. I. Sagatun, and F. G. Nielsen, "Wave synchronizing crane control during water entry in offshore moonpool operations-experimental result", IEEE Journal of Oceanic Engineering, Vol. 28, pp. 720-728, October, 2003.

[7] B. Skaare, and O. Egeland O, "Parallel force/position crane control in marine operation ", IEEE Journal of Oceanic Engineering, Vol. 31, pp. 599-613, July, 2006

[8] W. X. Wang, Y.M. Gong, X. H. Lai, X. J. Yu, and Z. H. Huang, "Technical analysis on offshore drilling draw works heave compensation system", Oil Field Equipment, Vol. 12, PP. 18-21, December, 2010.
[9] M. Velardocchia, and A. Vigliani, "Control systems integration for enhanced vehicle dynamics", The Open Mechanical Engineering Journal, vol. 7, pp. 58-69, September, 2013.

[10] A. Traverso, R. Bertone, and A. F. Massardo, "Transient Modelling of a Rotary-Kiln Pyrolyser", The Open Mechanical Engineering Journal, vol. 1, pp. 1-13, August, 2007.

[11] C. J. Kempf, and S. Kobayashi, "Disturbance observer and feed forward design for a high-speed-direct-drive positioning table", IEEE Transaction on Control System and Technology, Vol. 7, pp. 513-526, September, 1999.

[12] S. Zhou, Y. T. Li, G. Meng, and H. Ding, "Active vibration isolation with switching control method based on disturbance observer", Journal of vibration and shock, Vol. 25, pp. 121-123, June, 2006.

[13] H. S. Lee, Robust digital tracking controller for high speed highaccuracy positioning systems. California, Berkeley, 1994.

(C) Guo et al.; Licensee Bentham Open.

This is an open access article licensed under the terms of the Creative Commons Attribution Non-Commercial License (http://creativecommons.org/licenses/by-nc/3.0/) which permits unrestricted, non-commercial use, distribution and reproduction in any medium, provided the work is properly cited. 